\title{
OS PARADIGMAS EPISTEMOLÓGICOS DA MODERNIDADE E DA PÓS- MODERNIDADE: EDUCAÇÃO E DECOLONIALIDADE
}

\author{
José Eduardo Martins ${ }^{1}$ \\ Rosa de Lourdes Aguilar Verástegui ${ }^{2}$
}

\begin{abstract}
Resumo:
O presente artigo situa-se no contexto da pós-modernidade ao propor uma reconstrução epistêmica. Tem por objetivo analisar, a partir de uma perspectiva decolonial, o modo pelo qual a condição pós-moderna contribui para o resgate dos saberes ocultados pela modernidade eurocêntrica e, tendo em vista que a decolonialidade é um pensamento que surge contra um padrão colonial de poder. Sendo assim, procuraremos no artigo estabelecer um contato entre teoria pós-moderna e pensamento decolonial. Assim como modernidade e colonialidade andam juntas, pós-modernidade e decolonialidade também se aproximam, a diferença é que a primeira parte de uma razão dominadora e a segunda de uma razão libertadora. Para isso, buscaremos esclarecer as raízes do movimento decolonial latino-americano, bem como discutir a atualidade dos estudos decoloniais e seu impacto filosóficoeducacional na contemporaneidade, que chega atingir até o currículo de filosofia na educação superior. Isto se fará a partir de um lócus de enunciação bem determinado: a realidade socioeconômica, política e cultural latinoamericana. $\mathrm{O}$ artigo se apoia, em sua fundamentação teórica, no coletivo Modernidade/Colonialidade.
\end{abstract}

Palavras-chave: Colonialidade. Eurocentrismo. Pós-modernidade. Decolonialidade. Educação.

\section{THE EPISTEMOLOGICAL PARADIGMS OF MODERNITY AND POSTMODERNITY: EDUCATION AND DECOLONIALITY}

\begin{abstract}
:
The present article is located in the context of postmodernity when carrying out an epistemic reconstruction. It aims to analyze, from a decolonial perspective, the way in which the postmodern condition contributes to the rescue of knowledge hidden by eurocentric modernity and bearing in mind that decoloniality is a reality that appears influenced by postmodernity condition. Just as modernity and coloniality complements each other, so do postmodernity and decoloniality, the difference being that the first part of a dominating reason and the second part of a liberating reason. Ftor this, we will seek to clarify the roots of the Latin American decolonial movement as well as to discuss the currentness of decolonial studies and their philosophical-educational impact in contemporary times, which even reaches the philosophy curriculum in higher education. This will be done from a well-defined locus of enunciation: the socio-economic, political and cultural reality of Latin America. The article is based, in its theoretical foundation, on the Modernity/Coloniality collective.
\end{abstract}

Keywords: Coloniality. Eurocentrism. Post-modernity. Decoloniality. Education.

\footnotetext{
${ }^{1}$ Mestre em Gestão Educacional pelo Programa de Pós-Graduação em Educação da Universidade do Vale do Rio dos Sinos - (UNISINOS). Licenciado em Filosofia pela Universidade Federal de Santa Catarina - (UFSC). Membro do GP Filosofia, educação e condição humana. E-mail: jose.eduardo.martins@uel.br

${ }^{2}$ Professora Adjunta do Departamento de Educação, Comunicação e Artes da Universidade Estadual de Londrina - (CEMAD/UEL). Membro do Comitê de Ética em Pesquisa envolvendo Seres Humanos pela Universidade Estadual de Londrina - (CEP/UEL). Doutora em Filosofia da Educação pela Universidade Federal da Bahia (UFBA). Mestra em Filosofia pela Universidade Estadual de Campinas - (UNICAMP). Graduada em Filosofia pela Universidad Nacional Mayor de San Marcos - (UNMSM/PERU). Líder do GP Filosofia, educação e condição humana. E-mail: rosaguilar@uel.br
} 


\section{Introdução}

O paradigma científico moderno contribuiu com inegáveis avanços para a humanidade. A produtividade e o progresso em muitas áreas, tais como a produção de alimentos, a farmacologia, a medicina e, sobretudo hoje, as tecnologias da comunicação e informação, nos mostram isto. Porém, as consequências negativas deste modelo de racionalidade científica também se fizeram sentir. A destruição do meio ambiente, a ameaça nuclear e a corrida armamentista, o aquecimento global, entre outros, são consequências de uma racionalidade que se separou da natureza e ao fazer isto tornou-se uma ameaça para a vida em seu conjunto, incluindo a humana. A partir desta constatação negativa dos efeitos da racionalidade moderna dominante, uma parcela da sociedade e da comunidade científica e acadêmica em todo o mundo tem reagido e buscado novos caminhos.

Nesta procura surge o advento da pós-modernidade pode ser definido como uma condição reativa e de descrédito da sociedade em relação ao projeto iluminista da modernidade científica e suas grandes narrativas, fundamentadas em uma razão com pretensões de universalidade e verdades absolutas (LYOTARD, 1986). O irromper da pós-modernidade, por sua vez, abre a possibilidade para o desocultamento de saberes e visões de mundo outrora mantidos silenciados e esquecidos. É no interior desta nova condição epistêmica, fruto do desencanto em relação aos metarrelatos, utopias e promessas da modernidade eurocêntrica, que surgem os estudos decoloniais latino-americanos fomentados pela rede Modernidade/Colonialidade.

\section{A Rede Modernidade/Colonialidade}

Enquanto povos da América Latina, somos diferentes, é verdade, porém temos muitas semelhanças. Contudo, existe algo que nos cria estranhamentos, não conseguimos perceber as semelhanças históricas e identitárias. Paulo Freire (2010) afirma que, desde o período colonial, formou-se entre nós uma certa "cultura do silêncio" que proibia a expressão pessoal e cultural dos povos colonizados, tanto daqueles originários ou nativos quanto dos trazidos forçados do continente africano. Diante disto, podemos perguntar, parece-nos normal sermos mais próximos e semelhantes com os europeus do que com nossos irmãos e irmãs latinos?

$\mathrm{Na}$ realidade, os povos latino-americanos possuem raízes profundas, antigas e fortes que por conta de uma história marcada pela espoliação natural e cultural, fez com que essas raízes, assentadas em culturas milenares dos povos originários que aqui já viviam, fossem

\begin{tabular}{|l|l|l|l|l|}
\hline Qovista Qialectus & Ano 10 & n. 22 & Edição Especial, junho 2021 & p. 11 - 25 \\
\hline
\end{tabular}


desarticuladas ou parecessem separadas devido aos processos colonialistas de desumanização e alienação (DUSSEL, 1994).

O coletivo Modernidade/Colonialidade representa uma rede de intelectuais latinoamericanos, caribenhos, norte-americanos e europeus que buscam refletir determinadas categorias, questões e problemáticas a partir da realidade latino-americana, questionando os fundamentos políticos, epistemológicos e ontológicos enraizados na sociedade latinoamericana desde a colonização/invasão europeia ao continente. A respeito do coletivo Modernidade/Colonialidade, Escobar (2007, p.12) salienta que:

Mantendo o espírito do grupo, eu diria que este corpo de trabalho, ainda relativamente desconhecido no mundo de língua inglesa por razões que vão muito além da língua e que vão ao cerne do programa, constitui uma nova perspectiva da América Latina, mas não apenas para a América Latina, mas para o mundo das ciências sociais e humanas como um todo ${ }^{3}$ (tradução nossa).

A origem da Rede Modernidade/Colonialidade ocorre, segundo Grosfoguel (2010), em meados da década dos anos noventa, fruto de uma dissidência com o Grupo Latinoamericano de Estudos Subalternos que, apesar de empreender estudos a partir das camadas sociais subalternizadas ${ }^{4}$, produzindo conhecimentos desde a realidade cultural, política, social e econômica dos povos latino-americanos, o faziam utilizando bases conceituais, sistemas teóricos e esquemas explicativos oriundos de interpretações eurocêntricas sobre a América Latina. Era necessário, portanto, de acordo com o mesmo autor, transcender epistemologicamente os estudos críticos latino-americanos, substituindo-os por uma outra perspectiva, um pensamento crítico não mais subordinado aos cânones europeus, o que significa efetivar um giro epistemológico, superando aquilo que Boaventura de Sousa Santos denomina, por sua vez, de pensamento abissal:

O pensamento moderno ocidental é um pensamento abissal. Consiste num sistema de distinções visíveis e invisíveis, sendo que as invisíveis fundamentam as visíveis. As distinções invisíveis são estabelecidas através de linhas radicais que dividem a realidade social em dois universos distintos: o universo 'deste lado da linha' e o universo 'do outro lado da linha'. A divisão é tal que 'o outro lado da linha' desaparece enquanto realidade, torna-se inexistente, e é mesmo

\footnotetext{
3 "Manteniendo el espíritu del grupo, argumentaría que este cuerpo de trabajo, aún relativamente desconocido en el mundo angloparlante por razones que van mucho más allá del idioma y que hablan del núcleo del programa, constituye una novedosa perspectiva desde Latinoamérica, pero no sólo para Latinoamérica sino para el mundo de las ciencias sociales y humanas en su conjunto".

${ }^{4}$ Segundo o Dicionário gramsciano (2017), é inútil tentar definir a categoria de grupo ou classe subalterna em Gramsci porque não é uma entidade isolada nem homogênea. Ela compreende muitos componentes além de classe operária ou proletariado, são grupos sem coesão, que sofrem sempre a iniciativa dos grupos dominantes.
}

\begin{tabular}{|c|c|c|c|c|}
\hline QRovista Dialectus & Ano 10 & n. 22 & Edição Especial, junho 2021 & p. $11-25$ \\
\hline
\end{tabular}


produzido como inexistente. Inexistência significa não existir sob qualquer forma de ser relevante ou compreensível (SANTOS, 2010, p.31-32).

O pensamento abissal, derivado do paradigma científico moderno, é aquele tipo de pensamento que para existir necessita negar todas as outras formas possíveis de compreensão do mundo, cosmovisões outras e esquemas explicativos da realidade, silenciando-os e invisibilizando-os como não existentes. Somente assim foi possível à modernidade ocidental eurocêntrica desenvolver e manter uma epistemologia com pretensão de universalidade até os dias atuais.

Portanto, a Rede Modernidade/Colonialidade postula a necessidade de um giro epistemológico ou um pensamento pós-abissal que seja capaz de derrubar as máscaras encobertas pela modernidade, que questione a pretensão de toda e qualquer teoria de se autoproclamar e se autocompreender como universal, única e verdadeira em detrimento da exclusão e invisibilização de saberes outros (SANTOS, 2010).

Deste modo, o coletivo denominado Modernidade/Colonialidade tem buscado constituir-se num projeto de desconstrução do paradigma de poder/saber colonial e reconstrução e afirmação de um modelo de pensamento de fronteira, ou seja, saberes "de" e "a partir" dos sujeitos negados historicamente por uma hierarquia epistemológica e ontológica instalada desde o período colonial e presente até nossos dias na forma contemporânea de colonialidade (QUIJANO, 2010).

Segundo Grosfoguel (2010), os conhecimentos silenciados pelo processo colonizador necessitam ser desocultados através da elaboração de um pensamento de fronteira que atue como uma resposta epistêmica a partir dos sujeitos subalternizados:

As epistemologias de fronteira subsumem/redefinem a retórica emancipatória da modernidade a partir das cosmologias e epistemologias do subalterno, localizadas no lado oprimido e explorado da diferença colonial, rumo a uma libertação descolonial em prol de um mundo capaz de superar a modernidade eurocentrada (GROSFOGUEL, 2010, p.481).

A coletividade de argumentação decolonial vem criticar e questionar a hegemonia do saber, ser e poder instituído como epistemologia dominante. A crítica afirma que, os padrões cognitivos que se autodenominam únicos e universais, negam a existência da diversidade epistemológica porque têm a intenção de reproduzir e controlar o conhecimento. E estes padrões acabam por negar outras formas de saber e de ser, particularmente o saber e ser latinoamericano.

A pluralidade epistemológica torna visível espectros mais amplos de estudo, que não implica um relativismo epistemológico, senão uma visão que exige uma análise e avaliação

\begin{tabular}{|l|l|l|l|l|}
\hline Qovista Dialectus & Ano 10 & n. 22 & Edição Especial, junho 2021 & p. 11 - 25 \\
\hline
\end{tabular}


José Eduardo Martins / Rosa de Lourdes Aguilar Verástegui mais complexa da realidade através de diferentes formas de conhecimento. A diversidade epistemológica estabelece intricadas relações no interior da ciência e ainda com outros conhecimentos e condições sociais. Esta proposta epistemológica é denominada epistemologias do Sul e procura observar o e impacto do capitalismo no conhecimento e no desenvolvimento das ciências. As epistemologias do Sul levam em conta que o colonialismo constituiu uma dominação epistemológica com repercussões políticas, econômicas, educativas e sociais, entre outras consequências (SANTOS; MENESES, 2010).

Apesar do surgimento do coletivo Modernidade/Colonialidade ter ocorrido na metade da década de 90, a genealogia decolonial deita suas raízes em movimentos sociais e acadêmicos anteriores, tais como a filosofia da libertação do filósofo argentino Enrique Dussel; a sociologia da libertação do colombiano Orlando Fals Borda; os estudos dos intelectuais caribenhos Franz Fanon e Aimé Césaire; os movimentos de educação popular e a pedagogia do oprimido do brasileiro Paulo Freire; a teoria da dependência da comissão econômica para a América Latina e o Caribe (CEPAL) e a teologia da libertação latino-americana (ESCOBAR, 2007).

Deste modo, todos os atores acima mencionados têm em comum a busca pelo desvelamento da realidade latino-americana encoberta por séculos de dominação colonial, que perduram até os dias atuais. As roupagens mudam, mas a fome e a sede de exploração e dominação sobre o continente continuam acontecendo sob a forma de colonialidade cultural.

\section{A Colonialidade e suas dimensões}

De acordo com o coletivo Modernidade/Colonialidade, o conceito de colonialidade possui três dimensões distintas, mas ao mesmo tempo entrelaçadas, que são: a colonialidade do poder, a colonialidade do saber e a colonialidade do ser.

Mas o que se entende por colonialidade? Qual a origem do termo? De acordo com Quijano (2010), o termo colonialidade, embora vinculado ao conceito de colonialismo, é diferente deste:

Este último refere-se estritamente a uma estrutura de dominação/exploração onde o controle da autoridade política, dos recursos de produção e do trabalho de uma população determinada domina outra de diferente identidade e cujas sedes centrais estão, além disso, localizadas noutra jurisdição territorial. Mas nem sempre, nem necessariamente, implica relações racistas de poder. O colonialismo é, obviamente, mais antigo, enquanto a Colonialidade tem vindo a provar, nos últimos 500 anos, ser mais profunda e duradoira que o colonialismo. Mas foi, sem dúvida, engendrada dentro daquele e, mais ainda, sem ele não poderia ser imposta na intersubjetividade do mundo tão enraizado e prolongado (QUIJANO, 2010, p. 84).

\begin{tabular}{|c|c|c|c|c|}
\hline Qovista Dialectus & Ano 10 & n. 22 & Edição Especial, junho 2021 & p. $11-25$ \\
\hline
\end{tabular}


O que Quijano define com o conceito de colonialidade é, portanto, um dos elementos constitutivos do padrão mundial de poder capitalista, originado a partir do "descobrimento" da América, que irá se estender sobre todo o mundo sob influência do ocidente imperialista (Europa e depois Estados Unidos), como um prolongamento no tempo e no espaço do colonialismo originário. E após seu término do colonialismo, com a emancipação política das colônias, mantêm-se a dominação enraizada nas estruturas sociais, políticas e culturais dessas antigas colônias, agora sob a forma de colonialidade cultural (QUIJANO, 2010).

Deste modo, a colonialidade, além da sua dimensão de poder exercido sob a forma de exploração/domínio econômico, se apresenta também em duas outras dimensões: a do saber e a do ser. Isto porque o processo de colonização estabeleceu inicialmente uma geopolítica da economia centrada nos países colonizadores, e manteve uma geopolítica do conhecimento (após a emancipação política), ou seja, aquelas condições epistêmicas que possibilitaram a reprodução do saber dominante de matriz europeia, o fenômeno do eurocentrismo (DUSSEL, 2005).

Forjou-se, assim, a partir da conquista colonial do "novo mundo", a "América", um pretenso saber universal que ajudou a ocultar os interesses de dominação dos países colonizadores. A esse respeito, Quijano (2010, p.85) salientará que:

\footnotetext{
Desde o século XVII, nos principais centros hegemónicos desse padrão mundial de poder, nessa centúria, não sendo um acaso a Holanda (Descartes, Spinoza) e a Inglaterra (Locke, Newton), desse universo intersubjetivo, foi elaborado e formalizado um modo de produzir conhecimento que dava conta das necessidades cognitivas do capitalismo: a medição, a externalização (ou objetivação) do cognoscível em relação ao conhecedor, para o controle das relações dos indivíduos com a natureza e entre aquelas em relação a esta, em especial a propriedade dos recursos de produção.
}

Portanto, a colonialidade do saber foi sendo gestada e implementada em conformidade e simultaneamente com a colonialidade do poder em vista da expansão do capitalismo. Em outras palavras, o domínio e a exploração dos colonizadores europeus sobre os povos recém conquistados ou trazidos à força da África negra para o continente latinoamericano como mão de obra escrava, precisou de um aliado à altura da ganância e sede de poder e lucro dos colonizadores europeus. Esse aliado foi a colonialidade do saber que buscou invisibilizar, ocultar e inferiorizar os saberes dos povos nativos originários e dos negros escravizados e, deste modo, promover como saber único e legítimo o saber europeu (BALLESTRIN, 2013).

\begin{tabular}{|l|l|l|l|l|}
\hline Q ovista Dialectus & Ano 10 & n. 22 & Edição Especial, junho 2021 & p. 11 - 25 \\
\hline
\end{tabular}


Por outro lado, a colonialidade do poder e a colonialidade do saber só se tornaram possíveis pelo fato de ter existido uma negação ontológica como uma forma de ética do dominador (DUSSEL, 1994). Nesse sentido, os colonizadores cristãos europeus, inferiorizando a humanidade dos povos colonizados, do indígena primeiro e mais tarde a do africano escravizado, atribuem sua aventura de conquista e destruição alheia como um ato salvacionista e civilizador:

Uma vez provada a justiça da expansão europeia como uma obra civilizadora, emancipadora da barbárie a que estavam submetidos, tudo o resto (a conquista pelas armas, a espoliação do ouro e da prata referidos, o declarar os índios 'humanos' em abstrato, mas não as suas culturas, uma organização política em que o poder reside nas instituições colônias, a imposição de uma religião estrangeira de uma forma dogmática etc.) fica justificado (DUSSEL, 2010, p. 356).

Os colonizadores vêm aos povos conquistados como seres bárbaros, que devem ser civilizados através de uma cultura europeia. E assim inicia a marginalização das culturas nativas e a tentativa de erradicação as tradições (como se foram nocivas), para dar lugar a uma totalidade cultural europeia, fechada e imposta. Essa é uma dominação cultural que leva a uma alienação dos povos conquistados, porque nega-se a eles a possibilidade de olhar sua realidade, suas tradições e culturas, e se acaso ainda lembrem delas o façam com vergonha ou desprezo como se foram resquícios de um passado supostamente bárbaro.

Os colonizados nunca foram respeitados senão instrumentalizados, explorados e para justificar esta condição são excluídos, considerados como seres estranhos, diferentes. E assim é visto como um “Outro", portanto, desde a conquista da América, as culturas ameríndias e demais culturas não europeias vêm sendo construídas como o Outro negado. Um Outro tratado como objeto, como coisa passível de ser dominada, subjugada e explorada. É justamente esta ética da negação ontológica do Outro como um ser, como um sujeito, que possibilitará a imposição da cultura do dominador sobre as subjetividades dos povos ameríndios e dos africanos escravizados na forma de colonialidade do saber (DUSSEL, 1997).

\section{Colonialidade do saber e o ensino de filosofia}

Na América Latina, o colonialismo e suas dimensões de poder, ser e saber, engendraram uma cultura hegemônica que acabou por excluir saberes, conhecimentos e práticas dos povos colonizados as quais não se enquadravam nos cânones da cultura dominante do colonizador europeu. Essa supressão de conhecimentos, saberes e práticas culturais resultou num epistemicídio, ou seja, uma quase total aniquilação e desaparecimento das formas e saberes próprios dos povos colonizados e subjugados (SANTOS, 2010).

\begin{tabular}{|l|l|l|l|l|}
\hline Qevista Q Dialectus & Ano 10 & n. 22 & Edição Especial, junho 2021 & p. $11-25$ \\
\hline
\end{tabular}


As universidades, por sua vez, legitimaram e reforçaram historicamente o predomínio do saber e conhecimento europeu sobre os saberes e conhecimentos dos povos não europeus, produzindo concepções, conteúdos e práticas predominantemente eurocêntricas, silenciando as manifestações epistêmicas e culturais não europeias. Sendo assim, na universidade encontra-se presente o fenômeno da colonialidade do saber. Nas escolas e universidades brasileiras e latino-americanas a história tem sido estudada a partir da visão do colonizador europeu e a filosofia pensada a partir da tradição filosófica europeia (SANTOS, 1997).

De acordo com Brandão (2002), toda educação é cultura, pois, no tecer cultural, as relações sociais em determinados momentos se constituem como relações educativas no e com o mundo, engendrando diversas maneiras de interações de saberes. Na América Latina, a colonialidade do poder, ser e saber estabeleceu hierarquias culturais, uma cultura hegemônica que exclui as práticas e saberes culturais que não fazem parte do inventário cultural dominante.

A universidade se localiza como um desses espaços de encontro, interação e socialização de saberes, logo, na universidade, está presente o fenômeno da colonialidade do saber, produzindo concepções, conteúdos e práticas atreladas a um pensamento eurocêntrico que considera como inexistentes as manifestações epistêmicas latino-americanas (SANTOS, 2011). As universidades, as práticas educativas trazem consigo traços históricos que mostram a colonialidade do saber. Por isso, para compreender o movimento histórico nessas tramas é preciso uma análise dialética. A esse respeito, Konder (2004) afirma que:

Tudo tem a ver com tudo, os diversos aspectos da realidade se entrelaçam e, em diferentes níveis, dependem uns dos outros, de modo que as coisas não podem ser compreendidas isoladamente, uma por uma, sem levarmos em conta a conexão que cada uma delas mantém com coisas diferentes. Conforme as conexões (quer dizer, conforme o contexto em que ela esteja situada), prevalece, 'na coisa', um lado ou o outro da sua realidade (que é intrinsicamente contraditória). Os dois lados se opõem e, no entanto, constituem uma unidade (KONDER, 2004, p.58-59).

O caráter histórico-dialético significa dizer que os fenômenos da realidade se contrapõem, estão em movimento de negação e se co-determinam; bem como estão em movimento de composição, ou seja, a realidade possui uma unidade diversa, isto é, heterogeneamente contraditória. Por exemplo, no período colonial os saberes são formados pelas práticas dos saberes dos colonizadores, impostas de modo violento contudo, de forma resistente os saberes dos colonizados permaneceram vivos como uma forma de resistência, mesmo não sendo permitido pelos grupos dominantes. Isto significa que o saber mais autoritário e totalizante possuía, por mínimo que seja, oposições epistêmicas, saberes que foram marginalizados, porém re-existiram à dominação colonial (WALSH, 2009).

\begin{tabular}{|l|l|l|l|l|}
\hline Qevista Qialectus & Ano 10 & n. 22 & Edição Especial, junho 2021 & p. 11 - 25 \\
\hline
\end{tabular}


A questão do eurocentrismo no campo da filosofia será problematizada por Dussel (1977), quem observa a hegemonia de uma ontologia tradicional totalitária. "O ser" se torna monopólio do dominador e os povos dominados são identificados com o não-ser. Esta visão pode ser denominada "ontologia da totalidade" e visa abarcar toda a realidade, não abrindo possibilidade do ser exterior a si. A tradição ontológica eurocentrista nega a existência de um ser fora do perímetro europeu, capaz de refletir, questionar e filosofar. Para esta visão filosófica, o “ser” é europeu e o "não ser” são os outros. Daí a negação de uma filosofia Latinoamericana, Asiática ou Africana.

A reflexão filosófica dos povos excluídos pela ontologia europeia, pode ser vista como uma visão de mundo dos que estão fora do perímetro europeu, dos povos periféricos. Estes povos, através da visão periférica, alimentam-se de filosofia europeia e produzir sua própria filosofia, que não é uma cópia, senão uma filosofia autêntica. Esta filosofia periférica leva em conta a filosofia tradicional, as próprias experiências e suas tradições ancestrais, milenares (DUSSEL, 1977).

Ao observar os cursos de Filosofia nas instituições de ensino superior no Brasil, encontramos que os currículos destes cursos fazem pouca ou nenhuma alusão ao pensamento latino-americano e a filósofos latino-americanos. Ocorre que um currículo eurocêntrico impossibilita o desenvolvimento de epistemologias desde a subalternidade, desde "o não ser", desde a alteridade não europeia. A colonialidade do saber imprime nos desenhos curriculares um modo hegemônico de pensar e produzir conhecimento, que é o modo europeu de produzir conhecimento, de pensar e fazer filosofia e ciência, enfim, de educar.

De acordo com Arroyo (2012), o sistema educacional na América Latina encontrase:

[...] associado a um padrão cognitivo e pedagógico que tem operado com padrões de classificação social, étnica, racial, de gênero, de hierarquização e bipolaridades cognitivas dos coletivos humanos: coletivos primitivos, irracionais, incultos, selvagens, ignorantes, segregados do poder versus coletivos racionais, cultos, civilizados, detentores do poder/saber (ARROYO, 2012, p. 38-39).

O modelo educativo eurocêntrico tende, portanto, a marginalizar os sujeitos, os saberes, as espistemologias, as filosofias e pedagogias que divergem do seu padrão de classificação. Tal arrogância epistêmica exclui os saberes da experiência cotidiana, os saberes populares que fazem parte da realidade.

A Universidade Popular no Brasil, no contexto da educação do campo, tem buscado romper com a invisibilidade e o silenciamento dos saberes populares e dos sujeitos produtores

\begin{tabular}{|l|l|l|l|l|}
\hline Q ovista Qialectus & Ano 10 & n. 22 & Edição Especial, junho 2021 & p. 11 - 25 \\
\hline
\end{tabular}


de tais saberes. Esta proposta educativa procura articular novas lógicas de racionalidade fundamentada nos princípios da pedagogia ação-transformação como aporte teórico, construindo uma epistemologia transgressora e uma ciência descolonial ${ }^{5}$ na reinvenção da universidade pública (SILVA, 2020).

A subalternização de saberes torna evidente o silenciamento de outras formas de produzir conhecimento, que não estejam alinhados e subordinados ao paradigma hegemônico da elaboração de conhecimento, como é o caso dos saberes dos povos camponeses, indígenas, ribeirinhos e afrodescendentes, entre outros, que têm inviabilizada a sua produção de epistemologias e filosofias (DUSSEL, 1997; SANTOS, 2010).

No que se refere à investigação de um curso de licenciatura em filosofia de uma universidade estadual do Paraná realizado pelos autores do presente artigo, a análise do ementário das disciplinas acadêmicas do curso em questão, indica que sua estrutura curricular segue um padrão tradicional eurocêntrico de construção do conhecimento filosófico. Sendo assim, foi observado em apenas duas disciplinas da grade curricular do curso de licenciatura em filosofia da universidade pesquisada, de um total de 28 disciplinas obrigatórias ofertadas durante os quatro semestres de duração total do curso, a presença de alguma temática que problematizasse realidades mais próximas do contexto latino-americano e brasileiro. $\mathrm{Na}$ disciplina 1FIL051 - Núcleo Teórico/Prático de Filosofia Política - temos menção a história e cultura afro-brasileira e africana; e na disciplina 1 FIL055 - Núcleo Teórico/Prático de Metafísica, Subjetividade e Estética - temos menção ao tema da diversidade étnico-racial, de gênero, sexual, religiosa e de faixa geracional.

Pode-se dizer que a menção e o estudo de temas problematizadores de questões de diversidade étnico-raciais, de gênero e sexuais e o estudo de história e cultura afro-brasileira, em duas das disciplinas do curso de licenciatura em filosofia da referida universidade, é em si um avanço. Isto significa uma tentativa de romper com a hegemonia filosófico-educacional eurocêntrica presente no currículo do curso investigado.

Nos últimos anos, inúmeras iniciativas têm surgido no sentido de promover uma maior visibilidade em relação aos saberes e cultura dos grupos sociais minoritários e suas lutas históricas. Ribeiro (2019) destaca que em virtude da força dos movimentos negros no Brasil

\footnotetext{
${ }^{5}$ Catherine Walsh (2009) sinaliza uma diferença no emprego do termo descolonial e decolonial. A categoria descolonial faz referência a uma condição geopolítica de deixar de ser uma colônia, enquanto decolonial aponta para as resistências e lutas históricas na manutenção e preservação da própria cultura. 
iniciou-se uma crescente discussão a respeito do racismo estrutural presente na sociedade brasileira com o aumento na produção de materiais didáticos, saltos no número de publicações científicas, formação de grupos e linhas de pesquisa que tratam de temas relacionados as questões étnico-raciais.

No entanto, é preciso ressaltar que ainda existe uma invisibilidade acentuada nas disciplinas dos cursos de filosofia no Brasil de temáticas que não estejam atreladas ao cânone filosófico europeu. Segundo Nascimento e Botelho (2010):

A última discussão no Ministério da Educação sobre o currículo de filosofia que se verteu em normatização acontecerá em 2001, com a publicação das Diretrizes Curriculares para o Curso de Graduação em Filosofia. Ali, basicamente, as mesmas estruturas curriculares que pensavam o curso de filosofia cinquenta anos antes continuariam vigentes. Estas mesmas estruturas continham implícitas um brusco silenciamento da produção filosófica latino-americana e, sobretudo, a brasileira (NASCIMENTO; BOTELHO, 2010, p.67).

Decorre, portanto, da manutenção de uma estrutura curricular filosófica eurocentrada, inclusive nos documentos educacionais oficiais brasileiros, a naturalização de um silenciamento acadêmico dos saberes e culturas de grupos sociais minoritários: o indígena, o negro, o latino-americano. Um silenciamento que induz a pensar estes grupos como incapazes de produzirem conhecimentos válidos e filosofia autêntica.

Oliveira e Albuquerque (2010) trazem para o debate da filosofia da educação a problemática da negação da filosofia indígena. De acordo com as autoras, há nos processos educativos e epistemológicos a reprodução de um modelo moderno/colonial hegemônico de fazer filosofia, impossibilitando deste modo qualquer tentativa de compreensão de uma filosofia indígena. Segundo as autoras, é necessário repensar desde uma perspectiva filosóficoeducacional intercultural:

Repensar a própria filosofia, para além da postura histórica que a manteve atrelada ao
conhecimento erudito, distanciada dos saberes do cotidiano e silenciadora das práticas e
processos de formação humana que se inscreve dentro de outras lógicas. Repensar a filosofia a
partir de um olhar intercultural significa romper com a visão eurocêntrica em que ela
historicamente se assenta e reconhecer uma episteme no saber dos indígenas e de tantos outros
grupos que se encontram à margem [...] (OLIVEIRA, ALBUQUERQUE, 2010, p.13).

Este reconhecimento e valorização dos saberes indígenas e de outros grupos sociais minoritários deve passar, portanto, por um repensar a filosofia desde uma perspectiva filosófico-educacional intercultural. A temática das diferenças culturais precisa continuar a ser debatida em nossos espaços institucionais acadêmicos nos quais a crescente presença de estudantes provenientes destes grupos sociais minoritários, como indígenas e afrodescendentes, entre outros, nos desafiam a sair do lugar comum. O olhar intercultural sobre a filosofia é, portanto, um caminho possível no sentido de romper com a hegemonia da visão

\begin{tabular}{|l|l|l|l|l|}
\hline Q ovista Dialectus & Ano 10 & n. 22 & Edição Especial, junho 2021 & p. $11-25$ \\
\hline
\end{tabular}


José Eduardo Martins / Rosa de Lourdes Aguilar Verástegui eurocêntrica sobre o pensar filosófico, resgatando e valorizando outros saberes, outras formas de construir conhecimento, outros modos de enxergar a realidade, de outros pontos de vista, pois que todo ponto de vista é sempre a vista a partir de um ponto específico que, assim sendo, não é e nem pode ser totalizante, mas parte constitutiva de um todo maior e inesgotável.

Por isso podemos parafrasear a Dussel quando diz: “A América não há sacudido ainda suas correntes, arrasta-se acima das pegadas com os olhos vendados; não respira em suas

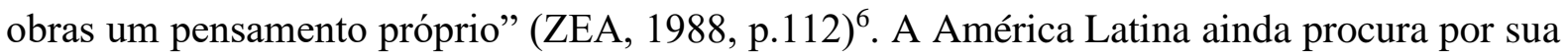
originalidade, e ela deve ser encontrada em suas raízes que fortalecem sua identidade, e deve observar que os povos europeus que se nomearam centro do mundo às custas das periferias, utilizam suas vantagens econômicas para legitimar sua dominação ao mesmo tempo em que negam a alteridade das culturas.

\section{Considerações finais}

O presente artigo deseja reforçar a hipótese de que o estudo de filosofia no Brasil e demais países latino-americanos estão envoltos em matrizes de saber que produzem desigualdades na distribuição, acesso e produção deste saber. Os saberes considerados relevantes pela tradição filosófica ocidental são, em sua maioria, os saberes europeus. Na academia brasileira e, sobretudo, nas disciplinas dos cursos de filosofia, o que se verifica é um silenciamento dos saberes dos povos originários ameríndios e afrodescendentes. E verificamos a quase inexistência de estudos e reflexões que busquem pensar e conceituar a filosofia a partir do contexto específico do continente latino-americano.

Tentar criar uma identidade latino-americana é tão difícil como observar uma identidade europeia, pela complexidade da população que a compõe. Assim, descobrir e reconhecer as características dos povos latino-americanos, permite observar a riqueza da diversidade étnica e cultural. Esta aproximação cultural poderá colaborar na consolidação de uma integração da América Latina, que nos leve além de pactos econômicos e que fortaleça a solidariedade entre seus povos.

Para cumprir a tarefa de consolidar a identidade latino-americana, as universidades precisam auspiciar estudos interdisciplinares sobre a realidade latino-americana e assim poder aspirar a ter uma consciência integracionista. Problematizar a realidade latino-americana é um

6 “La América no há sacudido aún sus cadenas; se arrastra sobre nuestras huellas con los ojos vendados; no respira en sus obras un pensamiento própio"

\begin{tabular}{|c|l|l|l|l|}
\hline Rovista Dialectus & Ano 10 & n. 22 & Edição Especial, junho 2021 & p. $11-25$ \\
\hline
\end{tabular}


desafio para a academia e especificamente para a filosofia, a antropologia filosófica. Porque uma perspectiva de filosofia e educação decolonial requer pensar desde um outro lócus de enunciação, que é o dos sujeitos e culturas subalternizadas pela colonialidade.

A observação da realidade do Outro, permitirá conhecer outra história e outras problemáticas, que proporcionaram novas propostas epistêmicas e novas lógicas educativas brotarão do solo fecundo dos saberes dos povos do continente latino-americano. A filosofia que surge da realidade Latino-americana é alimentada pela filosofia tradicional, mas não é cópia do pensamento alheio, senão criação autêntica, original. Como nos recorda Zea (1988), a barbárie está em querer ser como o colonizador, a ponto de perder a própria identidade, anulando as próprias tradições, renegando os seus valores e desistindo de sua criatividade.

\section{Referências bibliográficas}

ARROYO, Miguel. Outros Sujeitos, Outras Pedagogias. Petrópolis, RJ: Vozes, 2012.

BRANDÃO, Carlos Rodrigues. A educação como cultura. São Paulo: Mercados das Letras, 2002.

BALLESTRIN, Luciana. América Latina e o giro decolonial. Revista Brasileira de Ciência Política, n.11. Brasília, maio-agosto de 2013. Disponível em: http://www.periodicos.unb.br/index.php/rbcp/article/view/2029. Acesso em: 11 abril 2021.

DUSSEL, Enrique. 1492: el encubrimiento del otro - hacia el origen del mito de la modernidad. UMSA. Facultad de Humanidades y Ciencias de la Educación. Plural Editores. La Paz. $1994 . \quad$ Disponível em: http://bibliotecavirtual.clacso.org.ar/clacso/otros/20111218114130/1492.pdf. Acesso em: 09 abril 2021.

DUSSEL, Enrique. Europa, modernidade e eurocentrismo. In: LANDER, Edgardo (Org.). A Colonialidade do Saber: Eurocentrismo e Ciências Sociais perspectivas latino-americanas. Colección Sur-Sur. Ciudad Autonoma de Buenos Aires, Argentina: CLACSO, 2005. Disponível em: http://bibliotecavirtual.clacso.org.ar/clacso/sursur/20100708034410/lander.pdf. Acesso em: 09 abril 2021.

DUSSEL, Enrique. Filosofia da Libertação. São Paulo: Edições Loyola: Editora UNIMEP, 1977.

DUSSEL, Enrique. Oito ensaios sobre cultura latino-americana e libertação. São Paulo: Paulinas, 1997.

DUSSEL, Enrique. Meditações Anticartesianas sobre a origem do antidiscurso filosófico da modernidade. In: SANTOS, Boaventura de Sousa; MENESES, Maria Paula (Org.). Epistemologias do Sul. São Paulo: Cortez, 2010.

\begin{tabular}{|c|l|l|l|l|}
\hline Q Rovista Qialectus & Ano 10 & n. 22 & Edição Especial, junho 2021 & p. $11-25$ \\
\hline
\end{tabular}


ESCOBAR, Arturo. Mundos y conocimientos de otro modo. El programa de investigación de modernidade/colonialidad latinoamericano. In: SAAVEDRA, José Luis (comp.). Educación superior, interculturalidad y descolonización. La Paz: Fundación PIEB; CEUB, 2007. Disponível em: http://ayalaboratorio.com/2020/04/07educacion-superior-inlerculturalidad--ydecolonizacion/. Acesso em: 04 abril 2021.

FREIRE, Paulo. Liberdade Cultural na América Latina. In: STRECK, Danilo (Org.). Fontes da pedagogia latino-americana: uma antologia. Belo Horizonte: Autêntica Editora, 2010.

GROSFOGUEL, Ramón. Para descolonizar os estudos de economia política e os estudos póscoloniais: transmodernidade, pensamento de fronteira e colonialidade global. In: SANTOS, Boaventura de Sousa e MENESES, Maria Paula (Org.). Epistemologias do Sul. São Paulo: Cortez, 2010.

LIGUORI, Guido. VOZA, Pasquale. (org.). Dicionário Gramsciano (1926-1937). São Paulo: Boitempo, 2017.

LYOTARD, Jean François. A condição pós-moderna. José Olympio, 1986.

KONDER, Leandro. O que é dialética. São Paulo: Editora Brasiliense, 2004.

NASCIMENTO, Wanderson Flor do; BOTELHO, Denise. Colonialidade e Educação: O currículo de filosofia brasileiro entre discursos coloniais. Revista Sul-Americana de Filosofia e Educação. Número 14: mai-out, 2010. Disponível em: http://periodicos.unb.br/index.php/resafe/article/view/4398. Acesso em 18 abril 2021.

OLIVEIRA, Ivanilde Apoluceno; ALBUQUERQUE, Maria Betânia Barbosa. Filosofia, Cultura e Educação indígena. In: HENNING, Leoni Maria Padilha. Pesquisa, ensino e extensão no campo filosófico-educacional: debate contemporâneo sobre a educação filosófica. Londrina: EDUEL, 2010.

QUIJANO, Anibal. Colonialidade do poder e classificação social. In: SANTOS, Boaventura de Sousa e MENESES, Maria Paula (Org.). Epistemologias do Sul. São Paulo: Cortez, 2010.

RIBEIRO, Djamila. Pequeno manual antirracista. $1^{a}$ ed. São Paulo: Companhia das Letras, 2019.

SANTOS, Boaventura de Sousa; MENESES, Maria Paula (Org.). Epistemologias do Sul. São Paulo: Cortez, 2010.

SANTOS, Boaventura de Sousa. Pela mão de Alice: O social e o político na pós-modernidade. 4. ed. São Paulo: Cortez, 1997.

SANTOS, Boaventura de Sousa. A universidade no Século XXI: para uma reforma democrática e emancipatória da universidade. 3.ed. São Paulo: Cortez, 2011.

SILVA, Maria do Socorro Pereira. Educação do campo e o paradigma da extensão descolonial na universidade pública. Revista Iberoamericana de Estudos em Educação, Araraquara, v. 15, n. esp. 3, p. 2382-2395, nov; 2020. E-ISSN: 1982-5587. DOI: https://doi.org/10.21723/riaee.v15iesp3.14447. Acesso em: 20 abril 2021.

\begin{tabular}{|c|c|c|c|c|}
\hline Qovista Dialectus & Ano 10 & n. 22 & Edição Especial, junho 2021 & p. $11-25$ \\
\hline
\end{tabular}


José Eduardo Martins / Rosa de Lourdes Aguilar Verástegui

WALSH, Catherine. Interculturalidade crítica e pedagogia Decolonial: in-surgir, reexistir e reviver. In: CANDAU, Vera (Org.). Educação Intercultural na América Latina: entre concepções, tensões e propostas. Rio de Janeiro: 07 Letras, 2009.

ZEA, Leopoldo. Discurso desde la Marginación e la Barbarie. México: Fondo de Cultura Económica, 1988. 